\title{
Enhanced platelet adhesion in essential thrombocythemia after in vitro activation
}

\author{
In vitro aktivasyon sonrası esansiyel trombositemide yüksek platelet \\ adezyonu
}

\author{
Andreas C. Eriksson 1 , Kourosh Lotfi², Per A. Whiss ${ }^{1}$ \\ ${ }^{1}$ Division of Drug Research/Pharmacology, Department of Medical and Health Sciences, Linköping University, Sweden and \\ Department of Hematology, University Hospital, Linköping, Sweden \\ 2Division of Drug Research/Clinical Pharmacology, Department of Medical and Health Sciences, Linköping University, Sweden
}

\begin{abstract}
Objective: Essential thrombocythemia (ET) is a chronic myeloproliferative disorder characterized by elevated platelet counts and increased risk of thrombosis. Ex vivo data suggest increased platelet reactivity in agreement with the increased thrombosis risk, while in vitro tests often detect decreased platelet activity. The present study aimed to investigate adhesion of ET-platelets in vitro, which is an aspect of platelet function that has been addressed in only a few studies on ET patients. Material and Methods: The study included 30 ET patients and 14 healthy controls. Platelet adhesion was measured with a static platelet adhesion assay.

Results: The main finding was that ET-platelets were more readily activated by adhesion-inducing stimuli in vitro than control platelets. This was particularly evident in elderly patients and when using multiple stimuli, such as surfaces of collagen or fibrinogen combined with addition of adenosine 5'-diphosphate or ristocetin. Such multiple stimuli resulted in adhesion above the control mean +2 standard deviations for approximately $50 \%$ of the patients.

Conclusion: The results are in accordance with the concept of increased platelet activity in ET, but opposite to most other in vitro studies. We suggest that the conditions in the adhesion assay might mimic the in vivo situation regarding the presence of chronic platelet activation.

(Turk J Hematol 2010; 27: 82-90)

Key words: Essential thrombocythemia, platelet activation, adhesion, thrombosis, platelet assay

Received: December 4, 2009 Accepted: February 22, 2010

\section{Özet}

Amaç: Esansiyel trombositemi (ET) platelet sayısının artması ve yüksek tromboz riski ile karakterize kronik bir myeloproliferatif bozukluktur. Ex vivo veriler tromboz riskine uygun olarak artan platelet reaktivitesini öne sürerken in vitro testler sıklıkla platelet aktivitesinde azalma tespit etmektedir. Bu çalışmanın amacı ET-hastalarında az sayıda çalışmaya dahil edilmiş bir platelet fonksiyonu konusu olan ET-plateletleri adezyonunun in vitro incelenmesidir.

Yöntem ve Gereçler: Çalışmaya 30 ET hastası ile 14 sağlıklı kontrol dahil edilmiştir. Statik platelet adezyonu tayini ile platelet adezyonu ölçülmüştür.

Bulgular: Temel bulgu ET plateletlerinin, in vitro adezyon indüklenmiş uyaranlar ile kontrol plateletlerinden daha kolay aktive olduğu olmuştur. Bu durum özellikle yaşlı hastalarda ve adenosin 5-difosfat ya da ristosetin eklenerek kombine edilmiş kolajen ya da fibrinojen yüzeyler gibi çoklu uyaran kullanıldığında barizdir. Bu gibi çoklu uyaran hastaların yaklaşık \%50'sinde kontrol değeri + 2 standart sapmanın üzerinde adezyon sonucunu vermiştir.
\end{abstract}


Sonuç: Bulgular ET'de artan platelet aktivitesi konseptine uygun olsa da diğer in vitro çalışmaların tersinedir. Adezyon tayininde koşulların kronik platelet aktivasyonu varlığı ile ilgili olarak in vitro durumu taklit edebileceğini ileri sürüyoruz.

(Turk J Hematol 2010; 27: 82-90)

Anahtar kelimeler: Esansiyel trombositemi, platelet aktivasyonu, adezyon, tromboz, platelet tayini

Geliş tarihi: 4 Arallk 2009 Kabul tarihi: 12 Şubat 2010

Financial support: The study was financed by grants from the County Council of Östergötland (2004/049 and LIO-5311). During the course of the research underlying this study, Andreas C. Eriksson was enrolled in Forum Scientium, a multidisciplinary doctoral program at Linköping University, Sweden.

\section{Introduction}

Essential thrombocythemia (ET) is classified as a myeloproliferative neoplasm (MPN) [1] and affects about 1.5 middle aged to elderly individuals per 100,000 annually [2]. The disease is characterized by increased platelet counts and the occurrence of both thrombosis and bleeding [3]. Bleeding events are more common at very high platelet counts [4], probably as a consequence of the development of an acquired von Willebrand disease [5-7]. The most common complication is, however, thrombosis [3], which most often occurs in patients older than 60 years of age and in those with previous thrombosis [8]. Furthermore, a single point mutation in the JAK2 gene (Val617Phe) has been described [9-11], and is estimated to be present in about $60 \%$ of patients with ET [12]. The impact of this mutation on the risk of thrombotic complications is still controversial $[13,14]$. Treatment alternatives in ET include the use of cytotoxic drugs to lower platelet number and/or use of the platelet inhibitor acetylsalicylic acid (ASA) [15]. Guidelines for the use of these drugs were recently prepared after reviewing 438 papers published from 1980 to August 2002 [16]. It was concluded that treatment with ASA should be highly recommended for secondary thrombotic prophylaxis and for patients suffering from microcirculatory disturbances. However, the authors also discussed the lack of larger studies for this uncommon disease leading to difficulties in retrieving good scientific evidence for the best treatment in ET. Consequently, no consensus could be reached regarding ASA treatment as primary thrombotic prophylaxis.

One way of approaching this problem is to conduct further research on platelet function and on the thrombotic process in ET. Knowledge from such studies might be used to detect individual patients and/or define novel high-risk patient groups that would benefit from ASA. Several studies investigating platelet function in ET have already been performed. However, interpretations of the results are complicated since, depending

Table 1. Demographics of the included patients

\begin{tabular}{|c|c|}
\hline Gender (Male / Female) - n & $8 / 22$ \\
\hline Median age at blood sampling - years (range) & $67(30-87)$ \\
\hline Median age at diagnosis ${ }^{a}$ - years (range) & $61(31-84)$ \\
\hline Median time from diagnosis to blood sampling ${ }^{a}$ - years (range) & $7(1-27)$ \\
\hline \multicolumn{2}{|l|}{ Treatment at blood sampling - n (\%) } \\
\hline - ASA & $10(33.3)$ \\
\hline - $A S A+$ Hydroxyurea & $6(20.0)$ \\
\hline - No treatment & $5(16.7)$ \\
\hline - Hydroxyurea & $4(13.3)$ \\
\hline - Warfarin + Hydroxyurea & $2(6.7)$ \\
\hline - Warfarin + ASA & $1(3.3)$ \\
\hline - Warfarin & $1(3.3)$ \\
\hline - Interferon & $1(3.3)$ \\
\hline \multicolumn{2}{|l|}{ Disease historyb - n (\%) } \\
\hline - Thrombosis & $9(30.0)$ \\
\hline - No complications & $11(36.7)$ \\
\hline - Bleeding & $6(20.0)$ \\
\hline - Thrombosis + Bleeding & $4(13.3)$ \\
\hline
\end{tabular}

bDisease history includes events occuring before the time of blood sampling. Thrombosis events include deep vein thrombosis, thrombophlebitis, stroke, angina/myocardial infarction and transitory ischaemic attack. Bleeding events include haematoma, excessive menstruation, gum bleedings, haematuria, excessive bleedings from wounds, epistaxis and spontaneous bleedings 
on the assay used, both increased and decreased activity of ET-platelets have been reported [17]. In the present study, we used a novel assay of static platelet adhesion [18] to investigate platelet function in ET patients. The study used a screening approach and investigated adhesion to albumin, collagen, fibrinogen, and fibronectin in the presence of soluble activators such as adenosine 5'-diphosphate (ADP), adrenaline, ristocetin and $L$ - $\alpha$-lysophosphatidic acid (oleoyl-sn-glycero-3-phosphate, LPA). All of these surfaces and soluble activators, with the exception of albumin and ristocetin, are of obvious physiological importance. The inclusion of bacteria-derived ristocetin is motivated since it stimulates the otherwise flow-dependent interaction between von Willebrand factor (vWf) and glycoprotein (GP)-Ib-IX-V on platelets [19]. Albumin was included both as a negative control for basal adhesion and because it allows the detection of LPA-induced adhesion [20]. This experimental setup also allows investigation of both $\alpha_{2} \beta_{1}$-dependent adhesion to collagen and $\alpha_{\| \mathrm{b}} \beta_{3}$-dependent adhesion to fibrinogen and albumin [21]. Since platelet adhesion is scarcely studied in ET, our aim was to investigate if this novel assay for measurement of static platelet adhesion could be used to detect platelet abnormalities in patients with ET.

\section{Material and Methods}

\section{Patients and Control Subjects}

The study included 30 ET patients (Table 1), diagnosed according to the World Health Organization (WHO) classification of tumors for 2008. Inclusion was made consecutively during a one-year period. Fourteen healthy controls (4 female, 10 male) with a median age of 49 years (range: $31-66$ years) were also included. All controls were free from non-steroidal anti-inflammatory drugs or other drugs known to affect platelet function and were included consecutively during the same time period as the patients. The study conforms to the principles outlined in the Declaration of Helsinki (1975) and later revisions, and was approved by the ethical committee at the Faculty of Health Sciences in Linköping, Sweden (Dnr 03-043). All subjects gave their informed consent to be included in the study.

\section{Coating of Microplates}

The wells of 96-well microplates (Nunc Maxisorp, Roskilde, Denmark) were coated with different proteins by addition of $100 \mu \mathrm{L}$ of coating solution followed by incubation at $4^{\circ} \mathrm{C}$ at least overnight but for a maximum of 7 days. The different protein coating solutions consisted of $2 \mathrm{mg} / \mathrm{ml}$ human albumin (Pharmacia \& Upjohn AB, Stockholm, Sweden), 2 mg/ml human fibrinogen (American Diagnostica Inc., Greenwich, Connecticut, USA), $10 \mathrm{\mu g} / \mathrm{ml}$ human fibronectin (Roche Diagnostics, Mannheim, Germany) or $0.1 \mathrm{mg} / \mathrm{ml}$ collagen $\mathrm{S}$ from calf skin (Roche Diagnostics) combined with $2 \mu \mathrm{g} / \mathrm{ml}$ horse tendon collagen (Biopool International, Ventura, California, USA).

\section{Preparation of Platelet-Rich Plasma (PRP)}

Blood was drawn from antecubital veins into Na-heparin tubes and centrifuged at $205 \times \mathrm{g}$ for $20 \mathrm{~min}$ at room temperature $(R T)$. The upper layer consisting of PRP was transferred to a new tube and diluted $1: 4$ in a solution of $0.9 \% \mathrm{NaCl}$ containing $\mathrm{MgCl}_{2}$. The final concentration of $\mathrm{MgCl}_{2}$ when performing the platelet adhesion assay was $5 \mathrm{mmol} / \mathrm{L}$.

\section{Platelet Adhesion Assay}

Platelet adhesion was measured as previously described [18,21]. Briefly, protein-coated microplates were washed twice in $0.9 \% \mathrm{NaCl}$ by plate inversion followed by addition of $50 \mu \mathrm{L}$ diluted PRP and $50 \mu \mathrm{L}$ platelet activator or solvent. The platelet activators used were ADP and LPA (Sigma-Aldrich, St Louis, Missouri, USA), adrenaline (NM Pharma, Stockholm, Sweden) and ristocetin (Diagnostica Stago, Asnières-sur-Seine, France). The microplates were incubated for $1 \mathrm{~h}$ at RT to allow platelet attachment and, thereafter, washed twice in $0.9 \% \mathrm{NaCl}$ by plate inversion. To all wells, $140 \mu \mathrm{L}$ of a substrate buffer solution ( $\mathrm{pH} 5.4$ ) consisting of $0.1 \mathrm{~mol} / \mathrm{L}$ sodium citrate, $0.1 \mathrm{~mol} / \mathrm{L}$ citric acid, 0.1\% (w/v) Triton X-100 and $1 \mathrm{mg} / \mathrm{ml} p$-nitrophenyl phosphate (Sigma-Aldrich) was added. A separate microplate was used for estimation of $100 \%$ and $0 \%$ platelet adhesion. This was achieved by mixing $140 \mu \mathrm{L}$ substrate solution with 50 $\mu \mathrm{L}$ diluted PRP or $50 \mu \mathrm{L} 0.9 \% \mathrm{NaCl}$, respectively. Background absorbance was then measured for all wells at $405 \mathrm{~nm}$ using a Spectramax microplate reader (Molecular Devices, Sunnyvale, California, USA) and the microplates were incubated for 40 min during constant shaking at RT. After incubation, $100 \mu \mathrm{L}$ of 2 $\mathrm{mol} / \mathrm{L} \mathrm{NaOH}$ was added to all wells followed by absorbance measurements at $405 \mathrm{~nm}$. Percentage platelet adhesion was calculated from the absorbance values.

It has previously been shown that for absorbance values between 0 and 1 , the platelet count correlates well with the amount of product developed [18]. When performing the same type of analysis on one single patient with high platelet count we found that linear relationships between absorbance and platelet amount can be expected for absorbance values as high as $1.9\left(r^{2}=0.98\right)$.

\section{Allele-Specific Polymerase Chain Reaction (PCR)}

Blood samples from ET patients were analyzed for the JAK2 mutation (Val617Phe) as described earlier [9]. The only difference compared to the original protocol was the use of 35 PCR-cycles instead of 36.

\section{Statistics}

The effect of externally added platelet activators was analyzed with one-way Repeated Measures ANOVA followed by Bonferroni's multiple comparison test. Two-way ANOVA and Bonferroni's post test were used for comparisons between controls and patients. For the two-way ANOVA, all effects induced by externally added activators were analyzed as the effect measured reduced by the basal adhesion. The age distributions for controls and ET patients were analyzed with t-test and one-way ANOVA. The effect of JAK2 status on platelet adhesion was analyzed with t-test. Linear regression was used when investigating the influence of platelet amount on platelet adhesion and when analyzing the relationship between platelet amount and measured absorbance. All statistical calculations were performed using the software GraphPad Prism ${ }^{\circledR}$, version 4 (GraphPad Software Inc., San Diego, California, USA). 
Figure 1a

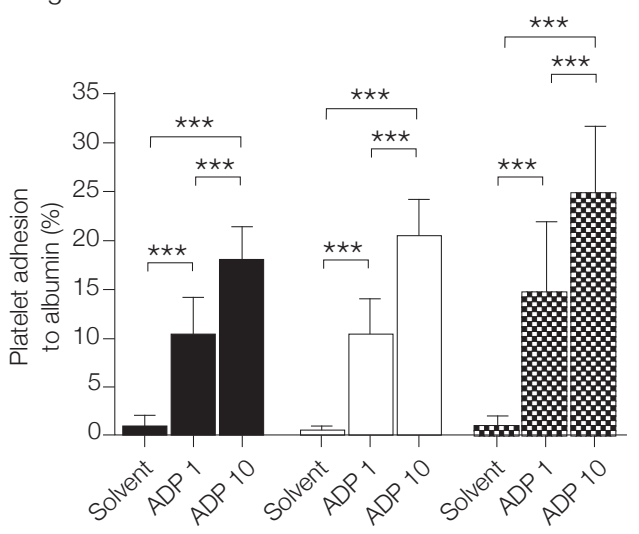

Figure 1c

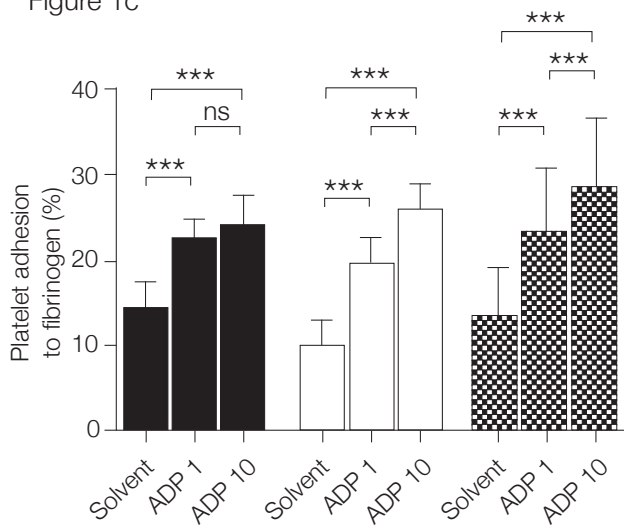

Figure 1b

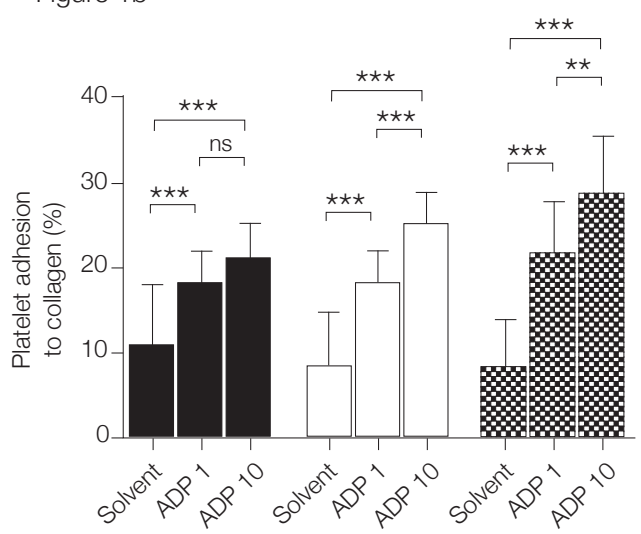

Figure 1d

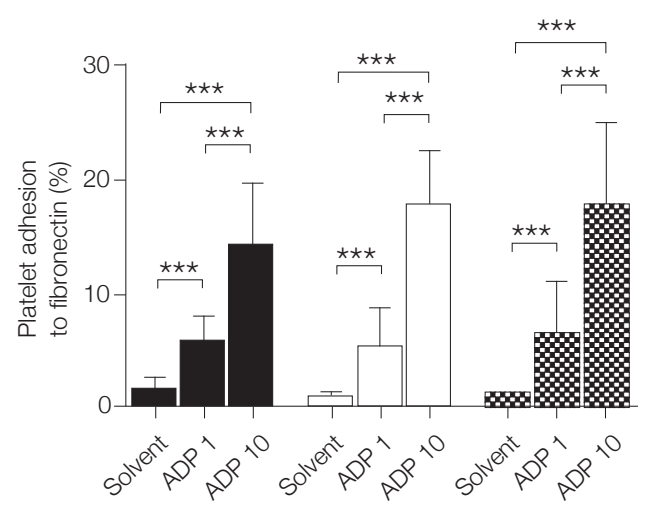

Figure 1. Platelet adhesion to albumin (a), collagen (b), fibrinogen (c), and fibronectin (d) was significantly increased by ADP (1 and $10 \mu \mathrm{mol} / \mathrm{L})$ for both controls and ET-platelets. A dose-response relationship was seen on all surfaces for ET-platelets, but only on albumin and fibronectin for controls. Differences in basal adhesion (solvent) between the three groups were not significant. Data are presented as mean+SD. Filled bars $=$ Controls $(n=11$ except for fibronectin where $n=10$, age range: $31-63$ years), open bars = Age-matched patients ( $n=14$, age range: $30-66$ years), patterned bars $=$ Patients $\geq$ 67 years $\left(n=16\right.$, age range: $67-87$ years). $n s=$ not significant, ${ }^{* *} p<0.01,{ }^{* \star *} p<0.001$

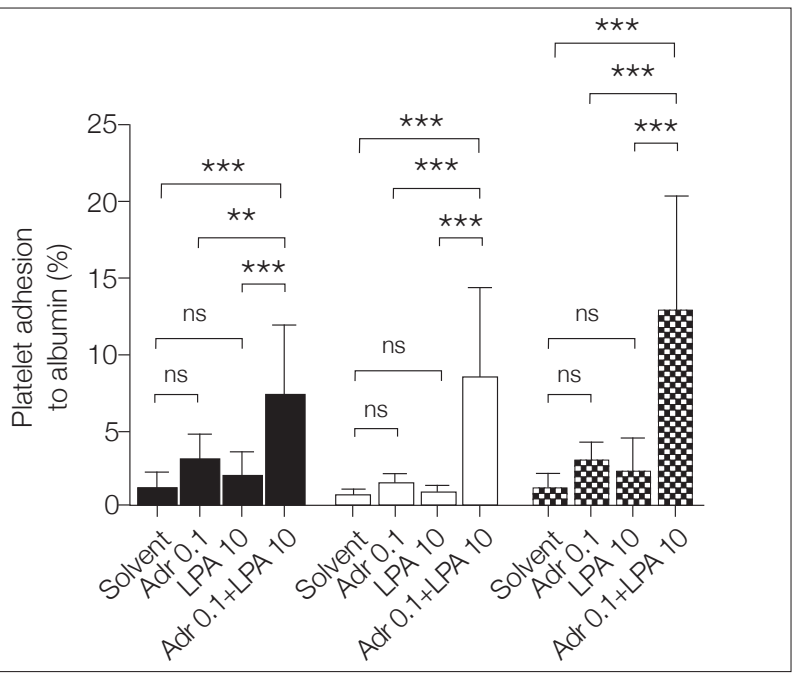

Figure 2. The combination of $0.1 \mu \mathrm{mol} / \mathrm{L}$ adrenaline (Adr) and $10 \mu \mathrm{mol} / \mathrm{L}$ LPA increased platelet adhesion synergistically to albumin for both ETplatelets and controls. Data are presented as mean+SD. Filled bars = Controls $(n=11$, age range: $31-63$ years), open bars = Age-matched patients ( $n=14$, age range: $30-66$ years), patterned bars $=$ Patients $\geq 67$ years $\left(n=16\right.$, age range: $67-87$ years). $n s=$ not significant, ${ }^{* \star} p<0.01,{ }^{\star \star *} p<0.001$

\section{Results}

The aim of this study was to investigate whether platelets from ET patients show abnormal adhesion patterns compared to controls. Several patients were older than 70 years, which resulted in difficulties in finding age-matched healthy controls. Consequently, the control group was significantly younger than the patient group $(p<0.01)$, and since age is considered a risk factor for thrombosis in ET [8], there is a potential risk that age might influence the results. To be able to compare the control group with the ET patients, we therefore divided the ET group in two, with one group being age-matched with the controls and the other group consisting of patients $\geq 67$ years. The ages of the controls ( $n=14$, median age: 49, range: 31-66) and the age-matched ET patients ( $n=14$, median age: 49, range: 30-66) were similar. However, the ages of the patients $\geq 67$ years ( $n=16$, median age: 77 , range: $67-87$ ) were significantly different from the other two groups $(p<0.001)$ The prevalence of ASA-treatment was similar for the age-matched ET patients (8 of 14) and the patients $\geq 67$ years (9 of 16). 


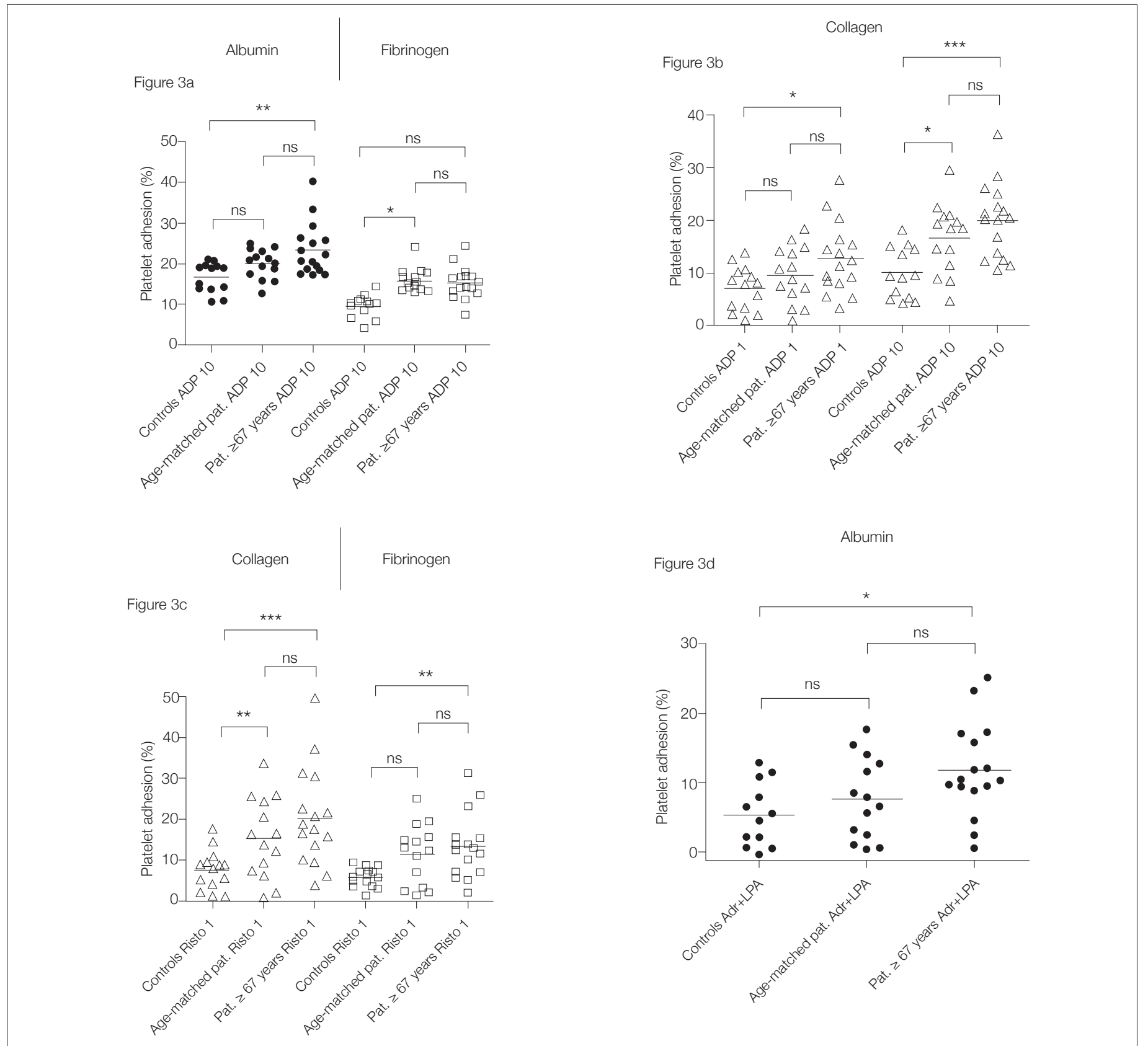

Figure 3. Platelet adhesion to albumin (filled circles), collagen (triangles) and fibrinogen (squares) induced by ADP (1 and $10 \mu \mathrm{mol} / \mathrm{L})$, ristocetin (Risto 1 $\mathrm{mg} / \mathrm{ml}$ ) or the combination of adrenaline (Adr $0.1 \mu \mathrm{mol} / \mathrm{L})$ and LPA $(10 \mu \mathrm{mol} / \mathrm{L})$ with basal adhesion subtracted. The increase in platelet adhesion induced by the soluble platelet activators was generally higher for ET patients compared to controls $(n=12-14$, age range: 31-66 years except in D where age range: 31-63 years) and there were no differences between age-matched patients ( $n=14$, age range: $30-66$ years) and patients $\geq 67$ years ( $n=16$, age range: 67-87 years). Horizontal lines represent mean values. $n s=$ not significant, ${ }^{*} p<0.05,{ }^{* *} p<0.01,{ }^{* * *} p<0.001$

Effect of Externally Added Platelet Activators on Platelet Adhesion

Our approach was to measure platelet adhesion to protein surfaces in the presence or absence of different externally added platelet activators. Basal adhesion to the different proteins in the absence of external activators (solvent) was not significantly different between the three groups (Figure 1). Addition of 1 and $10 \mu \mathrm{mol} / \mathrm{L}$ ADP significantly increased platelet adhesion to all surfaces for controls as well as for both patient groups (Figures 1a-d). Furthermore, there was a significant dose-response relationship on all surfaces when activating ET-platelets with ADP. For control platelets, this was only seen on albumin and fibronectin, i.e. the surfaces that induced the lowest adhesion. The only significant effects observed for adrenaline at $0.1 \mu \mathrm{mol} / \mathrm{L}$ and ristocetin at $1 \mathrm{mg} /$ $\mathrm{ml}$ were increased adhesion to collagen and fibrinogen for both ET-platelets and controls as well as increased ristocetininduced adhesion to albumin for ET-platelets (not shown). When combining $0.1 \mu \mathrm{mol} / \mathrm{L}$ adrenaline and $10 \mu \mathrm{mol} / \mathrm{L} \mathrm{LPA}$, 


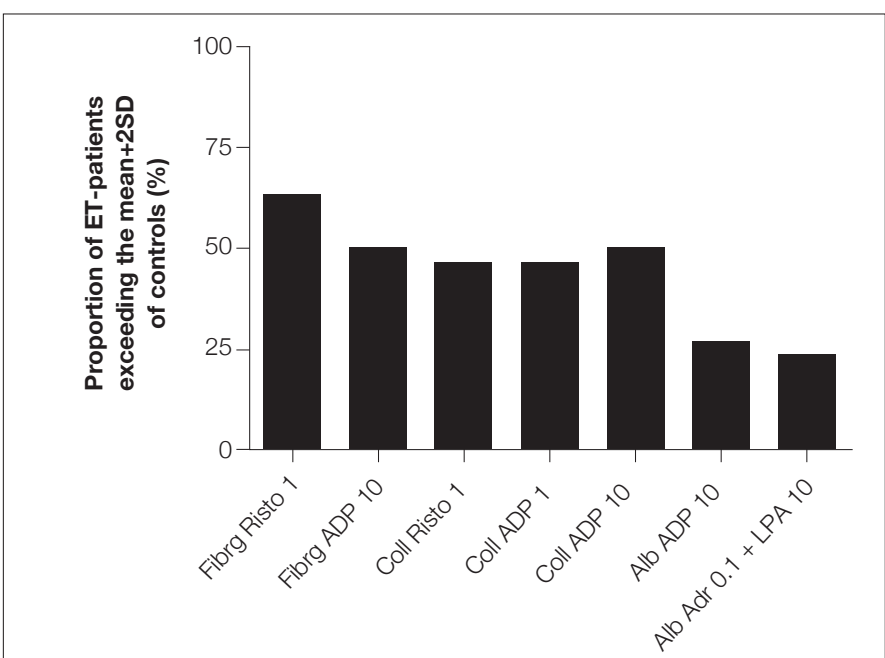

Figure 4. The relative proportion of all ET patients presenting with platelet adhesion to albumin (Alb), collagen (Coll) and fibrinogen (Fibrg) exceeding the mean $+2 S D$ of the control group for different activating stimuli with basal adhesion subtracted ( $n=30$, age range: $30-87$ years). Numerals on the $x$-axis represent concentrations of soluble platelet activators in $\mu \mathrm{mol} / \mathrm{L}$ except for ristocetin where the unit of concentration is $\mathrm{mg} / \mathrm{ml}$. Adr = adrenaline, Risto = ristocetin

adhesion of control- and ET-platelets to albumin was significantly increased compared to basal adhesion (solvent) and compared to adrenaline and LPA when added alone (Figure 2). This pattern of increased adhesion indicating synergistic effects was neither detected for controls nor ET-platelets on collagen and fibrinogen, but was present on fibronectin for both ET-groups but not for controls (not shown).

\section{Comparisons of Platelet Adhesion Between Controls and ET Patients}

When analyzing differences between the groups, we focused on those activators that produced significantly increased platelet adhesion for controls and both patient groups. Comparisons were made on the increase relative to basal adhesion induced by the externally added activators. For $10 \mu \mathrm{mol} / \mathrm{L}$ ADP on fibrinogen, the increase was significantly higher for age-matched patients compared to controls, while there was no difference between controls and patients $\geq 67$ years (Figure 3a). Inversely, adding $10 \mu \mathrm{mol} / \mathrm{L}$ ADP or the combination of adrenaline and LPA to albumin as well as $1 \mu \mathrm{mol} / \mathrm{L}$ ADP to collagen or $1 \mathrm{mg} / \mathrm{ml}$ ristocetin to fibrinogen resulted in significantly greater increase in adhesion for patients $\geq$ 67 years but not for age-matched ET patients compared to controls (Figures 3a-d). The increased adhesion to collagen induced by $10 \mu \mathrm{mol} / \mathrm{L}$ ADP and $1 \mathrm{mg} / \mathrm{ml}$ ristocetin was significantly higher for both age-matched patients and patients $\geq 67$ years compared to controls (Figures 3b, c). None of the activating stimuli induced significant differences between the patient groups (Figures 3a-d).

\section{Influence of Platelet Amount, History of Thrombohemorrhagic Events and JAK2 Status on Platelet Adhesion}

Since ET patients have more platelets than healthy individuals, we investigated if the increased platelet activity found in this study could be explained by this quantitative difference. In the cases where we observed a significant difference in the increase in platelet adhesion $(1 \mu \mathrm{mol} / \mathrm{L}$ ADP to collagen; 10 $\mu \mathrm{mol} / \mathrm{L}$ ADP to albumin, collagen and fibrinogen; $1 \mathrm{mg} / \mathrm{ml}$ ristocetin to collagen and fibrinogen; $0.1 \mu \mathrm{mol} / \mathrm{L}$ adrenaline +10 $\mu \mathrm{mol} / \mathrm{L}$ LPA to albumin), we performed linear regression analyses for the amount of ET-platelets added to wells versus platelet adhesion. Platelet amount was estimated by measurements of acid phosphatase activity, which correlates well with the actual platelet count [18]. However, there were no significant correlations between platelet amount and adhesion since $r^{2}$-values ranged from 0.0099 to 0.094 for the seven different stimuli.

Even though we found significant differences in platelet adhesion for ET patients compared to controls, we also found considerable variations within groups and consequently overlaps between the groups. We therefore further analyzed the results with specific attention to adhesion values for ET-platelets being higher than the mean + 2 standard deviations (SDs) calculated for controls (Figure 4) as described earlier [22]. Adhesion above mean +2 SD was found for approximately $50 \%$ of the patients when investigating ristocetin and ADPinduced adhesion to collagen and fibrinogen. The prevalence of such high adhesion values was considerably lower on the albumin surface. Furthermore, this pattern remained in both the age-matched patient group and in patients $\geq 67$ years (not shown). In order to investigate whether a high adhesion phenotype could be connected to a history of thrombosis, we studied the disease characteristics of patients having adhesion above mean $+2 \mathrm{SD}$ for five or more of the seven stimuli. However, this small group of nine patients was heterogeneous, containing patients suffering from bleeding and thrombosis as well as no events at all. At the time of blood sampling, five of those patients received a combination of anti-proliferative and anti-platelet treatment (hydroxyurea + ASA), one received hydroxyurea combined with warfarin, and three patients were untreated. Among the remaining 21 patients, three were treated with both anti-proliferative and anti-platelet drugs (ASA combined with hydroxyurea or with a history of P32-treatment). Also, for one of the three untreated patients in the high adhesion phenotype group, management of the disease was later changed to treatment with both hydroxyurea and ASA. A change from monotherapy into combined anti-platelet and anti-proliferative treatment (ASA+hydroxyurea or interferon) occurred in three patients in the larger group of 21 patients. We next investigated the influence on platelet adhesion of the recently discovered mutation in the JAK2 gene (Val617Phe), which is present in about 60\% of all ET patients [12]. JAK2 status was available for eight of the nine patients described above who had highly adhesive platelets (one patient died during the course of the study). Four of those patients were JAK2positive and four were JAK2-negative. Among all patients analyzed for JAK2 status in this study (25 patients), 15 were negative and 10 were positive. When investigating the whole patient group, there were no differences between JAK2positive and JAK2-negative patients regarding platelet adhesion induced by the stimuli that caused differences between controls and patients. 


\section{Discussion}

Different types of ex vivo platelet function measures have reported that ET-platelets are highly active. Flow cytometric studies in whole blood show increased platelet surface expression of P-selectin, increased binding of thrombospondin to platelets and increased amounts of platelet-leukocyte aggregates in MPN patients compared to controls [22,23]. Urine from ET patients has been reported to contain increased amounts of $\mathrm{TXA}_{2}$-metabolites [24]. Compared to normal subjects, an increased amount of platelet aggregates has been observed in blood from ET patients, and there is also an increased spontaneous aggregation of ET-platelets in plasma [25]. All those studies could potentially be used to explain the preponderance of thrombosis compared to bleeding in ET. However, interpretations get complicated when taking into account results obtained from analyses that activate platelets in vitro. In a study including 120 MPN patients, platelet aggregation was measured both in whole blood and in PRP after in vitro stimulation [26]. Platelets were hyperreactive when measuring whole blood aggregometry and using ADP and collagen as activators. In contrast, aggregation in PRP was decreased. Decreased platelet aggregation response in PRP to different platelet agonists for MPN patients has been reported by a number of other studies [27-30]. Decreased platelet function has also been observed with whole blood flow cytometry after in vitro activation [22] and when using the Platelet Function Analyzer (PFA-100) [30]. In accordance with this, we found a non-significant trend towards decreased basal adhesion to collagen and fibrinogen for ET-platelets in the present study. In contrast to these results, ET-platelets produce increased amounts of thromboxane $\mathrm{B}_{2}$ as compared to controls after in vitro stimulation with thrombin [31]. Regarding platelet aggregation in PRP, the most pronounced decrease in platelet function is often seen with adrenaline as activator [27,29,30]. This has been proposed to be the result of decreased amounts of $\alpha$-adrenergic receptors [32]. However, this is opposite to our results, which show that ET-platelets have normal response to adrenaline alone and increased reactivity compared to controls when combined with LPA. Further, we observed a considerable individual variability both in controls and in ET patients regarding the combination of adrenaline and LPA. The appearance of individual variability in the response to adrenaline has been studied in the healthy population, and when including 140 individuals, 16\% were classified as non-responders to adrenaline-induced platelet aggregation in plasma [33]. This variability in the adrenaline response in healthy subjects has been confirmed by other investigations also studying platelet function in plasma [20,34-36]. No study has been designed with the purpose of investigating individual variability of adrenaline-response in ET patients. However, when looking at individual variations obtained from studies investigating platelet aggregation in PRP for patients with MPNs, we find it possible that the variability exists in this group as well [30,32,37]. Particularly interesting is a study that investigated 76 MPN patients, and characterized $21 \%$ of patients as non-responders to adrenaline measured by aggregometry in PRP [27].
These results are very similar to the study on healthy donors described above, which reported $16 \%$ of healthy individuals as non-responders to adrenaline [33]. Our study, showing interindividual variation in the response to adrenaline combined with LPA, further supports the claim that the response to adrenaline in the ET population is highly heterogeneous. Furthermore, the increased response to adrenaline observed by us and not by others might be a result of the methodology used (described below).

Age is a well-known risk factor for thrombosis in ET $[8,38]$. In agreement with this, our results show higher adhesion values for patients $\geq 67$ years versus controls, which correlate well with the increased thrombosis risk in this group. We also found that some stimuli were significantly more effective in inducing platelet adhesion on age-matched patients compared to controls, while differences between the two patient groups were lacking. A plausible explanation is that part of the increase in adhesion is connected to old age while the other part is connected to the disease itself.

Our general finding in this study was that ET-platelets are more readily activated compared to controls. However, there was an overlap between the groups with several patients having responses in the same range as the control group. Since the JAK2 mutation occurs in only approximately 60\% of ET patients [12], we decided to investigate if patients with high adhesion values were JAK2-positive. However, JAK2 status did not influence platelet adhesion. Furthermore, there were no clear connections between platelet adhesion and disease history. On the other hand, this study included eight patients treated with ASA combined with anti-proliferative treatment, and five of those were classified as high adhesion phenotype. Later, one untreated patient that we classified as high adhesion phenotype was, independent of our results, prescribed ASA combined with hydroxyurea. From a clinical point of view, it might be suggested that these patients, being treated with both anti-proliferative and anti-platelet drugs, were considered to have a more severe disease and therefore needed more extensive treatment. The other patients not classified as high adhesion phenotype were less likely to have combined antiproliferative and anti-platelet treatment. In this way, a high adhesion phenotype seems to be connected to clinical status. However, further studies are needed before any definite conclusions can be drawn regarding the predictive value of the adhesion assay for thrombosis. We aim to follow these patients in the future, not only for the purpose of detecting thrombosisprone individuals but also for investigating the abilities of the assay to guide anti-thrombotic treatment.

It might be claimed that our use of PRP without the commonly performed adjustment of platelet count with autologous platelet-poor plasma (PPP) limits this study. However, recent studies have shown that adjustment of platelet count with PPP might induce decreased platelet activity, possibly through an inhibiting effect from PPP $[39,40]$. This suggests that comparisons between control platelets and platelets from ET patients might be misleading if adjusting the platelet count since the higher platelet count for ET patients demands more PPP for dilution [40]. Consequently, the increased adhesion for ET-platelets observed in this study might be the result of avoidance of PPP-induced artificial inhibition. 
It has been proposed that increased activity of ET-platelets in vivo results in circulating exhausted platelets that are not able to respond in vitro [41]. This explanation might also be of interest for the interpretation of the current results. We suggest that the increased reactivity in vitro observed by us, which is uncommon for other in vitro tests, might be a consequence of the relatively long one hour incubation period in the presence of both an activating surface and soluble agonists. This is rather different from e.g. flow cytometry and platelet aggregometry, which often measure platelet response within minutes after stimulation with a single agonist. We also noticed that strong stimuli such as high concentrations of ADP and ristocetin combined with the activating surfaces collagen and fibrinogen resulted in a relatively high proportion of adhesion values being higher than the mean + 2SD for controls. In contrast, weaker stimuli represented by adhesion measured on albumin resulted in comparatively few adhesion values that were higher than the control mean + 2SD. In addition, earlier studies show that secretion of ADP is important in this assay $[20,21]$. Thus, we propose that multiple stimuli, which most likely are of importance in vivo [42], and a long incubation time are both needed to induce secretion and activation of exhausted ET-platelets.

In conclusion, we suggest that the present platelet assay mimics the in vivo situation regarding the presence of chronic platelet-activating stimuli resulting in increased risk of thrombosis. It must be remembered, however, that additional factors, such as vascular cells other than platelets and shear stress, are absent in our assay but affect thrombus formation in vivo. Nevertheless, the assay is reproducible over time [43] and it might be useful to predict thrombotic risk and monitor antiplatelet treatment in ET. Further prospective follow-up studies and larger patient material are needed to strengthen this hypothesis.

\section{Conflict of interest}

No author of this paper has a conflict of interest, including specific financial interests, relationships, and/or affiliations relevant to the subject matter or materials included in this manuscript.

\section{References}

1. Vardiman JW, Thiele J, Arber DA, Brunning RD, Borowitz MJ, Porwit A, Harris NL, Le Beau MM, Hellstrom-Lindberg E, Tefferi A, Bloomfield CD. The 2008 revision of the World Health Organization (WHO) classification of myeloid neoplasms and acute leukemia: rationale and important changes. Blood 2009;114:937-51.

2. Johansson P. Epidemiology of the myeloproliferative disorders polycythemia vera and essential thrombocythemia. Semin Thromb Hemost 2006;32:171-3.

3. Elliott MA, Tefferi A. Thrombosis and haemorrhage in polycythaemia vera and essential thrombocythaemia. $\mathrm{Br} \mathrm{J}$ Haematol 2005;128:275-90.

4. van Genderen PJ, Michiels JJ. Erythromelalgic, thrombotic and haemorrhagic manifestations of thrombocythaemia. Presse Med 1994;23:73-7.
5. Budde U, Schaefer G, Mueller N, Egli H, Dent J, Ruggeri Z, Zimmerman T. Acquired von Willebrand's disease in the myeloproliferative syndrome. Blood 1984;64:981-5.

6. Budde U, Scharf RE, Franke P, Hartmann-Budde K, Dent J, Ruggeri ZM. Elevated platelet count as a cause of abnormal von Willebrand factor multimer distribution in plasma. Blood 1993;82:1749-57.

7. van Genderen PJ, Budde U, Michiels JJ, van Strik R, van Vliet $\mathrm{HH}$. The reduction of large von Willebrand factor multimers in plasma in essential thrombocythaemia is related to the platelet count. Br J Haematol 1996;93:962-5.

8. Cortelazzo S, Viero P, Finazzi G, D'Emilio A, Rodeghiero F, Barbui T. Incidence and risk factors for thrombotic complications in a historical cohort of 100 patients with essential thrombocythemia. J Clin Oncol 1990;8:556-62.

9. Baxter EJ, Scott LM, Campbell PJ, East C, Fourouclas N, Swanton S, Vassiliou GS, Bench AJ, Boyd EM, Curtin N, Scott MA, Erber WN, Green AR. Acquired mutation of the tyrosine kinase JAK2 in human myeloproliferative disorders. Lancet 2005;365:1054-61.

10. James C, Ugo V, Le Couedic JP, Staerk J, Delhommeau F, Lacout C, Garcon L, Raslova H, Berger R, Bennaceur-Griscelli A, Villeval JL, Constantinescu SN, Casadevall N, Vainchenker W. A unique clonal JAK2 mutation leading to constitutive signalling causes polycythaemia vera. Nature 2005;434:1144-8.

11. Levine RL, Wadleigh M, Cools J, Ebert BL, Wernig G, Huntly BJ, Boggon TJ, Wlodarska I, Clark JJ, Moore S, Adelsperger J, Koo S, Lee JC, Gabriel S, Mercher T, D'Andrea A, Frohling S, Dohner K, Marynen P, Vandenberghe P, Mesa RA, Tefferi A, Griffin JD, Eck MJ, Sellers WR, Meyerson M, Golub TR, Lee SJ, Gilliland DG. Activating mutation in the tyrosine kinase JAK2 in polycythemia vera, essential thrombocythemia, and myeloid metaplasia with myelofibrosis. Cancer Cell 2005;7:387-97.

12. Vannucchi AM, Guglielmelli P, Tefferi A. Advances in understanding and management of myeloproliferative neoplasms. CA Cancer J Clin 2009;59:171-91.

13. Tefferi A, Elliott M. Thrombosis in myeloproliferative disorders: prevalence, prognostic factors, and the role of leukocytes and JAK2V617F. Semin Thromb Hemost 2007;33:313-20.

14. Finazzi G, Barbui T. Evidence and expertise in the management of polycythemia vera and essential thrombocythemia. Leukemia 2008;22:1494-502.

15. Harrison CN, Green AR. Essential thrombocythaemia. Best Pract Res Clin Haematol 2006;19:439-53.

16. Barbui T, Barosi G, Grossi A, Gugliotta L, Liberato LN, Marchetti M, Mazzucconi MG, Rodeghiero F, Tura S. Practice guidelines for the therapy of essential thrombocythemia. A statement from the Italian Society of Hematology, the Italian Society of Experimental Hematology and the Italian Group for Bone Marrow Transplantation. Haematologica 2004;89:215-32.

17. Wehmeier A, Sudhoff T, Meierkord F. Relation of platelet abnormalities to thrombosis and hemorrhage in chronic myeloproliferative disorders. Semin Thromb Hemost 1997;23:391-402.

18. Eriksson AC, Whiss PA. Measurement of adhesion of human platelets in plasma to protein surfaces in microplates. J Pharmacol Toxicol Methods 2005;52:356-65.

19. Berndt MC, Shen Y, Dopheide SM, Gardiner EE, Andrews RK. The vascular biology of the glycoprotein Ib-IX-V complex. Thromb Haemost 2001;86:178-88. 
20. Eriksson AC, Whiss PA, Nilsson UK. Adhesion of human platelets to albumin is synergistically increased by Iysophosphatidic acid and adrenaline in a donor-dependent fashion. Blood Coagul Fibrinolysis 2006;17:359-68.

21. Eriksson AC, Whiss PA. Characterization of static adhesion of human platelets in plasma to protein surfaces in microplates. Blood Coagul Fibrinolysis 2009;20:197-206.

22. Jensen MK, de Nully Brown P, Lund BV, Nielsen OJ, Hasselbalch HC. Increased platelet activation and abnormal membrane glycoprotein content and redistribution in myeloproliferative disorders. Br J Haematol 2000;110:116-24.

23. Jensen MK, de Nully Brown P, Lund BV, Nielsen OJ, Hasselbalch HC. Increased circulating platelet-leukocyteaggregates in myeloproliferative disorders is correlated to previous thrombosis, platelet activation and platelet count. Eur J Haematol 2001;66:143-51.

24. Rocca B, Ciabattoni G, Tartaglione R, Cortelazzo S, Barbui T, Patrono C, Landolfi R. Increased thromboxane biosynthesis in essential thrombocythemia. Thromb Haemost 1995;74:1225-30.

25. Wu KK. Platelet hyperaggregability and thrombosis in patients with thrombocythemia. Ann Intern Med 1978;88:7-11.

26. Balduini CL, Bertolino G, Noris P, Piletta GC. Platelet aggregation in platelet-rich plasma and whole blood in 120 patients with myeloproliferative disorders. Am J Clin Pathol 1991;95:82-6.

27. Avram S, Lupu A, Angelescu S, Olteanu N, Mut-Popescu D. Abnormalities of platelet aggregation in chronic myeloproliferative disorders. J Cell Mol Med 2001;5:79-87.

28. Ginsburg AD. Platelet function in patients with high platelet counts. Ann Intern Med 1975;82:506-11.

29. Yamamoto K, Sekiguchi E, Takatani O. Abnormalities of epinephrine-induced platelet aggregation and adenine nucleotides in myeloproliferative disorders. Thromb Haemost 1984;52:292-6.

30. Cesar JM, de Miguel D, Garcia Avello A, Burgaleta C. Platelet dysfunction in primary thrombocythemia using the platelet function analyzer, PFA-100. Am J Clin Pathol 2005;123:772-7.

31. Mayordomo O, Carcamo C, Vecino AM, Navarro JL, Cesar JM. Arachidonic acid metabolism in platelets of patients with essential thrombocythaemia. Thromb Res 1995;78:315-21.

32. Kaywin P, McDonough M, Insel PA, Shattil SJ. Platelet function in essential thrombocythemia. Decreased epinephrine responsiveness associated with a deficiency of platelet alphaadrenergic receptors. N Engl J Med 1978;299:505-9.

33. Kambayashi J, Shinoki N, Nakamura T, Ariyoshi H, Kawasaki T, Sakon M, Monden M. Prevalence of impaired responsiveness to epinephrine in platelets among Japanese. Thromb Res 1996;81:85-90.

34. Nakahashi TK, Kambayashi J, Nakamura T, Le SN, Yoshitake $\mathrm{M}$, Tandon NN, Sun B. Platelets in nonresponders to epinephrine stimulation showed reduced response to ADP. Thromb Res 2001;104:127-35.

35. Pyo MK, Yun-Choi HS, Hong YJ. Apparent heterogeneous responsiveness of human platelet rich plasma to catecholamines. Platelets 2003;14:171-8.

36. Theodoropoulos I, Christopoulos C, Metcalfe P, Dimitriadou E, Economopoulos P, Loucopoulos D. The effect of human platelet alloantigen polymorphisms on the in vitro responsiveness to adrenaline and collagen. $\mathrm{Br} \mathrm{J}$ Haematol 2001;114:387-93.

37. Raszeja-Specht A, Skibowska A, Bieniaszewska M, Szutowicz A. Relationships between thrombohemorrhagic complications and platelet function in patients with essential thrombocythaemia. Am J Hematol 2001;68:32-6.

38. Landolfi R, Cipriani MC, Novarese L. Thrombosis and bleeding in polycythemia vera and essential thrombocythemia: pathogenetic mechanisms and prevention. Best Pract Res Clin Haematol 2006;19:617-33.

39. Cattaneo M, Lecchi A, Zighetti ML, Lussana F. Platelet aggregation studies: autologous platelet-poor plasma inhibits platelet aggregation when added to platelet-rich plasma to normalize platelet count. Haematologica 2007;92:694-7.

40. Grignani C, Noris P, Tinelli C, Barosi G, Balduini CL. In vitro platelet aggregation defects in patients with myeloproliferative disorders and high platelet counts: are they laboratory artefacts? Platelets 2009;20:131-4.

41. Michiels JJ, Berneman Z, Schroyens W, Finazzi G, Budde U, van Vliet $\mathrm{HH}$. The paradox of platelet activation and impaired function: platelet-von Willebrand factor interactions, and the etiology of thrombotic and hemorrhagic manifestations in essential thrombocythemia and polycythemia vera. Semin Thromb Hemost 2006;32:589-604.

42. Graff J, Klinkhardt U, Harder S. Pharmacodynamic profile of antiplatelet agents: marked differences between single versus costimulation with platelet activators. Thromb Res 2004;113:295-302.

43. Eriksson AC, Jonasson L, Lindahl TL, Hedback B, Whiss PA. Static platelet adhesion, flow cytometry and serum TXB2 levels for monitoring platelet inhibiting treatment with ASA and clopidogrel in coronary artery disease: a randomised cross-over study. J Transl Med 2009;7:42. 